\title{
Crystal Structure Analysis and the Identification of Distinctive Functional Regions of the Protein Elicitor Mohrip2
}

\author{
Mengjie Liu ${ }^{1}$, Liangwei Duan ${ }^{2}$, Meifang Wang ${ }^{1}$, Hongmei Zeng ${ }^{1}$, Xinqi Liu ${ }^{2 *}$ and \\ Dewen Qiu ${ }^{1 *}$
}

\begin{abstract}
' State Key Laboratory for Biology of Plant Diseases and Insect Pests, Institute of Plant Protection - Chinese Academy of Agricultural Sciences, Beijing, China, ${ }^{2}$ State Key Laboratory of Medicinal Chemical Biology, Department of Biochemistry and Molecular Biology, College of Life Sciences, Nankai University, Tianjin, China
\end{abstract}

\section{OPEN ACCESS}

Edited by:

Benjamin Schwessinger, Australian National University,

Australia

Reviewed by:

Simon John Williams, University of Queensland, Australia Lennart Wirthmueller, Free University of Berlin, Germany

${ }^{*}$ Correspondence:

Dewen Qiu

qiudewen@caas.cn

Xinqi Liu

liu2008@nankai.edu.cn

Specialty section:

This article was submitted to

Plant Biotic Interactions,

a section of the journal

Frontiers in Plant Science

Received: 05 May 2016

Accepted: 12 July 2016

Published: 26 July 2016

Citation:

Liu M, Duan L, Wang M, Zeng H, Liu X and Qiu D (2016) Crystal

Structure Analysis and the Identification of Distinctive Functional Regions of the Protein

Elicitor Mohrip2.

Front. Plant Sci. 7:1103.

doi: 10.3389/fpls.2016.01103
The protein elicitor MoHrip2, which was extracted from Magnaporthe oryzae as an exocrine protein, triggers the tobacco immune system and enhances blast resistance in rice. However, the detailed mechanisms by which MoHrip2 acts as an elicitor remain unclear. Here, we investigated the structure of MoHrip2 to elucidate its functions based on molecular structure. The three-dimensional structure of MoHrip2 was obtained. Overall, the crystal structure formed a $\beta$-barrel structure and showed high similarity to the pathogenesis-related (PR) thaumatin superfamily protein thaumatin-like xylanase inhibitor (TL-XI). To investigate the functional regions responsible for MoHrip2 elicitor activities, the full length and eight truncated proteins were expressed in Escherichia coli and were evaluated for elicitor activity in tobacco. Biological function analysis showed that MoHrip2 triggered the defense system against Botrytis cinerea in tobacco. Moreover, only MoHrip2M14 and other fragments containing the 14 amino acids residues in the middle region of the protein showed the elicitor activity of inducing a hypersensitive response and resistance related pathways, which were similar to that of full-length MoHrip2. These results revealed that the central 14 amino acid residues were essential for anti-pathogenic activity.

\section{Keywords: MoHrip2, crystal structure, truncated mutant, hypersensitive response, disease resistance}

\section{INTRODUCTION}

Plants survive under adverse circumstances including various of biotic factors because of a very effective immune system (Bernoux et al., 2011). The plant immune system is complex and consists mostly of two major branches of defense (Jones and Dangl, 2006; Mishra et al., 2012; Hou et al., 2013). One branch involves plant cell surface-located pattern recognition receptors (PRRs) that recognize pathogen-associated molecular patterns (PAMPs) and is named PAMP-triggered immunity (PTI). Another branch involves intracellular plant NLRs [nucleotidebinding, leucine-rich repeat (LRR) receptors] that recognize pathogen-secreted effectors and is called effector-triggered immunity (ETI). Understanding plant immunity mechanisms might provide new approaches to protect agricultural production (Dodds and Rathjen, 2010). The plant immune system is based on the effective detection and recognition of different inducers from 
the environment (Shamrai, 2014). As main inducers, elicitors (the term is defined by Dodds and Rathjen, 2010) to refer to both PAMPs and effectors in the context of this paper) have been intensely studied in the plant immunology field. In the last few decades, substantial progress has been made in the study of elicitors, including the identification of new elicitors and their corresponding receptors in plants and the analysis of their biological functions in vitro or in transgenic plants. Such work has revealed the molecular mechanisms of induced immunity that underlie elicitor recognition, defenserelated signaling transduction mechanisms, the defense response network and the evolution of plant immunity, among other processes (Dodds and Rathjen, 2010; Hwang et al., 2012; Hou et al., 2013; Chuang et al., 2014; Shamrai, 2014).

Furthermore, studies examining the crystal structures and functional regions of elicitors and receptors increasingly represent another intensely researched topic (Wirthmueller et al., 2013), and over the past 20 years, many elicitor structures have been resolved. These crystal structure studies provide evidence for the classification of new proteins and confirm the functions of elicitor proteins on a molecular level. For example, the effector AvrPphB is considered a papain-like cysteine protease to catalyze proteolysis based on its highly similar crystal structure (Zhu et al., 2004). Moreover, the structures of effectors and their receptors are currently being elucidated, and some effector-receptor complex structures have recently been reported (Maqbool et al., 2015), providing insight into their interactions and revealing mechanisms of the plant immune response. For example, the crystal structure of an AtCERK1ECD (the ectodomain of the chitin elicitor receptor kinase 1 from Arabidopsis) in complex with a chitin pentamer showed that the interaction is primarily mediated by a lysine motif and three chitin residues; dimerization of AtCERK1-ECD is induced by chitin and is critical for activating the plant immune system (Liu et al., 2012). Furthermore, structural studies can also be insightful to investigate evolutionary processes. Some inhibitors that act at the plant-pathogen interface evolved from enzymes (MisasVillamil and Ra, 2008). For example, the Triticum aestivum xylanase inhibitor (TAXI) is considered to have evolved from a pepsin-like aspartic protease ancestor based on an analysis of its crystal structure (Sansen et al., 2004). In addition to the ability to trigger plant immunity, elicitors might have other functions, such as the ability to suppress PTI. The identification of functional regions helps elucidate different elicitor functions. Structure-function experiments indicated that the 75 amino acid C-terminal half of AVR3a lacking the RXLR motif was sufficient for avirulence and suppression functions, and other regions showed no effector activity (Bos et al., 2006). Therefore, structure-function relationship studies provide a theoretical foundation to understand in detail the functions of elicitors in the plant immune system and the mechanisms through which they act.

Magnaporthe oryzae, a fungal pathogen of rice blast, is the most devastating rice pathogen and causes a destructive decrease in rice production in epidemic years (Dean et al., 2005). To understand the molecular basis of the rice- $M$. oryzae interaction, several elicitors of the fungal pathogen have been identified, including sphingolipid components of the membranes (Koga et al., 1998) and some avirulence (Avr) effectors (Liu et al., 2010). MoHrip2, a novel elicitor isolated from M. oryzae, is an exocrine protein. The 459 bp MoHrip2 open reading frame (GenBank accession no. JQ815555.1) encodes a 152 residue polypeptide with an 18 residue signal peptide. In our previous work, we showed that MoHrip2 causes necrotic lesions and triggers early signaling events in the tobacco leaf defense system, and we showed that MoHrip2 also enhanced resistance to $M$. oryzae in rice (Chen et al., 2014). Although, the MoHrip2 amino acid sequence showed up to $70 \%$ similarity to several specific plant fungal pathogen proteins (Chen et al., 2014), the specific function of both MoHrip2 and proteins with similar sequences are unknown.

In this study, we solved the crystal structure of MoHrip2 by X-ray crystallography using the single-wavelength anomalous dispersion (SAD) method. Based on the structure, the distinctive functional regions responsible for the hypersensitive response (HS) and the disease resistance of MoHrip2 were narrowed to a short sequence. Our results provide a framework to understand the function of MoHrip2 in the rice- $M$. oryzae interaction and to elucidate the mechanisms that trigger plant immunity. Furthermore, our results have potential as a strategy for using in vitro approaches or transgenic plants to control disease.

\section{MATERIALS AND METHODS}

\section{Crystallization and Structure Determination of MoHrip2}

Native or selenomethionine-labeled MoHrip2 was recombinantly expressed, purified, and crystallized. Protein expression, purification, crystallization, data collection, and structural determination were performed as described previously (Liu et al., 2013). The positions of all four selenium atoms in an asymmetric unit were successfully located from the peak data set, and the preliminary model was readily built following single-wavelength anomalous diffraction (SAD; Dauter et al., 2002) phasing using the Phenix package (Adams et al., 2010). The Phenix refinement program (phenix.refine; Afonine et al., 2012) was used iteratively for refinement. Simulated annealing, positional refinement and B-factor refinement were applied for multiple rounds. The electron density of loop regions became visible gradually as refinement proceeded. Structure validation was performed periodically during refinement by Procheck (Laskowski et al., 1993). Ordered water molecules were added to the structure in the last round of refinement.

\section{Plasmid Construction and Truncated Protein Expression and Purification}

To express truncated mutants of the MoHrip2 protein, DNA sequences encoding different fragments were amplified by PCR from plasmid pMDR18-T-mohrip2 (Liu et al., 2013) using the primers shown in Supplementary Table S1. The PCR cycles included pre-denaturation at $94^{\circ} \mathrm{C}$ for $5 \mathrm{~min} ; 30$ cycles of $94^{\circ} \mathrm{C}$ for $30 \mathrm{~s}, 55^{\circ} \mathrm{C}$ for $30 \mathrm{~s}$, and $72^{\circ} \mathrm{C}$ for $30 \mathrm{~s}$; and a final extension step at 
$72^{\circ} \mathrm{C}$ for $10 \mathrm{~min}$. The reaction product was separated on a $1.0 \%$ agarose gel and analyzed with a UV transilluminator (Bio-Rad Laboratories, Hercules, CA, USA). Gel extraction was performed using the EasyPure Quick Gel Extraction Kit (Transgen, Beijing, China) according to the manufacturer's instructions. Products of different sizes were cloned into the pET-30 TEV/LIC vector (Liu et al., 2013) downstream of a His 6 tag or into the BamHI/XhoI site of the pET-M3C vector [reconstructed from the pET-32a $(+)$ vector (Novagen) by the Xinqi Liu Laboratory to delete a thrombin recognition site, an S-tag and an enterokinase recognition site] downstream of a $\mathrm{His}_{6}$-Trx (thioredoxin) tag.

Recombinant expression vectors were transformed into Escherichia coli Codon Plus competent cells. The cells were cultured in $\mathrm{LB}$ medium at $37^{\circ} \mathrm{C}$ to an $\mathrm{OD} 600$ of 0.6 , then were induced with $0.2 \mathrm{mM}$ isopropyl $\beta$-D-1-thiogalactopyranoside (IPTG) for $12 \mathrm{~h}$ at $16^{\circ} \mathrm{C}$. Cell harvesting and the subsequent purification of proteins expressed in a soluble form or in inclusion bodies were performed as described previously (Han et al., 2012; Liu et al., 2013) using a Ni-IMAC matrix column. The empty pET-M3C vector was transformed into competent cells to produce an inactive protein preparation, named $\mathrm{His}_{6}$ Trx protein. The $\mathrm{His}_{6}$-Trx was expressed and purified using the same method and was used as a negative control. The eluted protein was concentrated and diluted with Tris buffer (50 mM Tris, $\mathrm{pH}$ 8.0) before detection using SDS-PAGE. The protein concentration was measured using the Bradford method (Bradford, 1976).

\section{Hypersensitive Response Induction Assay}

Nicotiana benthamiana and Nicotiana tabacum plants (78 weeks-old) were used for the HR assay. Full-length and truncated MoHrip2 proteins and a control were diluted to $5 \mu \mathrm{M}$ in Tris buffer, and $50 \mu \mathrm{L}$ was infiltrated into the leaves at locations between the midvein and the edge of the leaf with a needleless syringe. HR symptoms were observed in the infiltrated areas after $24 \mathrm{~h}$ according to a previously described method (D'Silva and Heath, 1997).

\section{Disease Resistance Induction Assay}

The fungus Botrytis cinerea was cultured on potato dextrose agar (PDA; BD Difco, Sparks, NV, USA) plates for 7-10 days at $25^{\circ} \mathrm{C}$ with a $12 \mathrm{~h}$ photoperiod. $N$. benthamiana (5-6 weeksold) were used for the disease resistance assay. Full-length and mutant proteins at the same concentration mentioned above were infiltrated into one side (separated by the center vein) of leaves using the same method described above. The leaves were cut off of the plants and placed in a $1 \%$ agar-medium plate $6 \mathrm{~h}$ postinfiltration (hpi). The inoculation experiment was performed according to a previously described method (Chagué et al., 2006). A $5 \mathrm{~mm}$ diameter mycelium cube cut from the edge of $B$. cinerea was placed on the other side of the protein-treated leaves between the midvein and the edge of the leaf. The plates were placed in an illumination incubator under the same conditions as the plants but at a high relative humidity (>90\%). The disease level was estimated by measuring the diameters or the major axes of the oval necrotic lesions around the inoculation sites 3 days post-inoculation (dpi; Ferrari et al., 2003).

\section{RNA Extraction and Quantitative Real-Time PCR}

Nicotiana benthamiana leaves were treated on one side (separated by the center vein) with the proteins described above using the above-described method. The other side of the treated leaves was harvested 6 hpi for RNA extraction and quantitative real-time PCR (qRT-PCR). Total RNA extracted using TRIzol Reagent (Invitrogen, Carlsbad, CA, USA) was reverse-transcribed into cDNA using TransScript All-in-One First-Strand cDNA Synthesis SuperMix for qPCR (Transgen, Beijing, China) according to the manufacturer's instructions. qRT-PCR was performed using TransStart Green qPCR SuperMix (Transgen, Beijing, China) and an iQ5 real-time PCR instrument (BioRad Laboratories, Hercules, CA, USA). The conditions for qRT-PCR included an initial denaturation at $95^{\circ} \mathrm{C}$ for $30 \mathrm{~s}$ that was followed by 42 cycles of $94^{\circ} \mathrm{C}$ for $5 \mathrm{~s}$ and $60^{\circ} \mathrm{C}$ for $30 \mathrm{~s}$. Actin was used as the reference gene, and all of the primers (listed in Supplementary Table S1) were designed using Beacon Designer 8. qRT-PCR was performed according to the Minimum Information for Publication of qRT-PCR Experiments (MIQE) standard (Bustin et al., 2009).

\section{RESULTS}

\section{The Crystal Structure of MoHrip2 Reveals a Thaumatin Domain-Like Fold}

To study the molecular functions of MoHrip2, the full-length protein lacking the signal peptide sequence was expressed, purified and crystallized, and the crystal structure was solved and refined to a resolution of $1.8 \AA$ (PDB 5FID). Refinement statistics are summarized in Table 1. The overall architecture is a $\beta$-barrel consisting of $11 \beta$-sheets and a very short $\alpha$-helix (Figure 1A). Apart from the N-terminal $(\beta 1)$ and C-terminal $(\beta 11)$ sheet, all of the other $\beta$-pleated sheets ran antiparallel within each $\beta$-pleated sheet. The short helix was located between the $\beta 9$ and $\beta 10$ sheet. MoHrip 2 contains six cysteines that are involved in three intramolecular disulfide bridges, which occur between cysteines 27 and 151, 116 and 140, and 121 and 129 (Figure 1B). The distribution of the electrostatic surface potentials are shown in Figure 1C, which are displayed in scale from $-52.24 \mathrm{kTV}$ (red) to $+52.24 \mathrm{kTV}$ (blue), with a negative-rich zone in the shown side. A DALI search (Holm and Rosenström, 2010) based on similarity to the MoHrip2 3-dimensional structure revealed that it has similarity to thaumatin/THN domain (PF00314 of Pfam ${ }^{1}$, and SM00205 of $\mathrm{SMART}^{2}$ )-containing proteins with the highest $\mathrm{Z}$ score in the screened proteins and root mean square deviation (RMSD) value more than 2 (Table 2 ). Thaumatin-like proteins (TLPs), including thaumatin, osmotin, zeamatin, pathogenesis-related $(\mathrm{PR})$ proteins and alpha-amylase/trypsin inhibitors, are involved

\footnotetext{
${ }^{1}$ http://pfam.xfam.org/

${ }^{2}$ http://smart.embl-heidelberg.de/
} 
TABLE 1 | X-ray crystallographic data and refinement statistics for selenomethionine-labeled MoHrip2-L78M.

\begin{tabular}{|c|c|}
\hline Date set & MoHrip2-L78M \\
\hline \multicolumn{2}{|l|}{ Data collection } \\
\hline Wavelength $(\AA)$ & 0.9792 \\
\hline Space group & P21 \\
\hline$a(\AA)$ & 36.25 \\
\hline $\mathrm{b}(\AA)$ & 43.51 \\
\hline$c(\AA)$ & 74.00 \\
\hline$\beta^{\circ}$ & 92.88 \\
\hline Resolution $(\AA)^{\mathrm{a}}$ & $1.8(1.86-1.8)$ \\
\hline Molecules per ASU ${ }^{\mathrm{b}}$ & 2 \\
\hline No. of observed reflections ${ }^{a}$ & $93203(6670)$ \\
\hline No. of unique reflections ${ }^{a}$ & $21184(1906)$ \\
\hline Completeness (\%) & $96.6(86.4)$ \\
\hline Redundancy ${ }^{\mathrm{a}}$ & $4.4(3.5)$ \\
\hline $\mathrm{R}_{\text {merge }}(\%)^{\mathrm{a}, \mathrm{c}}$ & $5.7(28.8)$ \\
\hline Average $\mathrm{I} / \sigma(\mathrm{I})^{\mathrm{a}}$ & $16.8(2.3)$ \\
\hline \multicolumn{2}{|l|}{ Refinement statistics } \\
\hline Resolution $(\AA)$ & 1.807 \\
\hline No. of reflection & 21175 \\
\hline Rwork/Rfree (\%) ${ }^{\mathrm{d}, \mathrm{e}}$ & $16.30 / 20.00$ \\
\hline \multicolumn{2}{|l|}{ No. of atoms } \\
\hline Protein & 2050 \\
\hline Water & 402 \\
\hline \multicolumn{2}{|l|}{ B-factor $\left(\AA^{2}\right)$} \\
\hline Protein & 15.22 \\
\hline Water & 23.73 \\
\hline \multicolumn{2}{|l|}{ r.m.s. deviations } \\
\hline Bond length $(\AA ̊)$ & 0.007 \\
\hline Bond angle $\left(^{\circ}\right)$ & 1.151 \\
\hline \multicolumn{2}{|l|}{ Ramachandran analysis } \\
\hline Favored (\%) & 96.59 \\
\hline Allowed (\%) & 3.41 \\
\hline Outliers (\%) & 0 \\
\hline
\end{tabular}

avalues in parentheses are for the highest resolution shell.

${ }^{\mathrm{b}} \mathrm{ASU}=$ asymmetric unit.

${ }^{\mathrm{c}} R_{\text {merge }}=\Sigma||-\langle|>|| \Sigma\langle 1\rangle$, in which I is the observed intensity, and $\langle 1\rangle$ is the average intensity of multiple observations of symmetry related reflections.

${ }^{\mathrm{d}} R=\Sigma h k \||| F_{\text {obs }}|-| F_{\text {calc }}|| / \Sigma h k|| F_{0}$ obs $\mid$.

${ }^{\mathrm{e}} R_{\text {free }}$ is calculated from $5 \%$ of the reflections excluded from refinement.

in the plant defense and stress response (Wang et al., 2013), and some TLPs have shown inhibition of fungal growth in vitro (Vigers et al., 1992). Thus, these proteins are referred to as pathogenesis-related group 5 (PR5).

Thaumatin-like proteins are predicted to consist mainly of $\beta$ structures, with a high content of $\beta$-turns and few helices (Edens et al., 1982). The most similar structure to MoHrip2 was that of a thaumatin-like xylanase inhibitor (TL-XI, PDB 3G7M), and their comparison is shown in Figure 2A. TL-XI is a novel type of xylanase inhibitor from wheat (T. aestivum) and is a non-competitive inhibitor of glycoside hydrolase family 11 (GH11) xylanase, which shows a unique inhibition specificity (Fierens et al., 2007). The MoHrip2 structure was also similar to that of NP24 (PDB 2IOW; Supplementary Figure S1A), which is a salt-induced protein from tomato. NP24 also has $\beta$-glucanase activity and antifungal properties and is involved in protecting plant cells from pathogens (Ghosh and Chakrabarti, 2008). The MoHrip2 structure was also similar to two other antifungal proteins, osmotin (PDB $1 \mathrm{PCV}$ ) and zeamatin (PDB 1DU5; Supplementary Figures S1B,C), which were purified from N. tabacum and Zea mays, respectively. Both of these proteins are involved in fungal plasma membrane permeabilization and are believed to be representatives of a class of plant antifungal proteins (Roberts and Selitrennikoff, 1990; Abad et al., 1996). Other than the thaumatin proteins, the MoHrip2 structure is also similar to the barrel domain of the protein Beta-1,3Glucanase (PDB 3GD9; Figure 2B), which is a GH64 protein from Streptomyces matensis (Wu et al., 2009). However, all of the proteins mentioned above show very low primary amino acid sequence homology (range from 9 to 16\%) to MoHrip2 (Supplementary Figure S2).

\section{Purified Full-Length and Truncated Forms of MoHrip2 Show Functional Differences in HR Induction}

To determine which region of MoHrip2 is critical for HR induction or for inducing resistance, several truncated mutants were designed using the structurally determined positions of the $\beta$-pleated sheet and $\alpha$-helix (Figure 3A). Each of the truncated mutants was expressed, purified and analyzed by SDS-PAGE (Figure 3B). The protein with $\mathrm{His}_{6}$ tag (MoHrip2, MoHrip $2 \triangle \mathrm{C} 22$, MoHrip $2 \triangle \mathrm{C} 27$, and MoHrip2 $\triangle$ C63) were expressed in inclusion bodies while the protein with $\mathrm{His}_{6}-\mathrm{Tr} \mathrm{x}$ (MoHrip2 $\triangle$ C77, MoHrip2 $\triangle$ N75, MoHrip2M50, MoHrip2M36, MoHrip2M14, and His 6 -Trx) in a soluble form. The theoretical value of the isoionic point, the number of amino acid residues, the expression vector used, the theoretical molecular weight, and other details of the truncated mutants are described in Supplementary Table S2. Initially, amino acid residues were deleted from the C-terminus, and four mutants were generated (MoHrip2 $\triangle \mathrm{C} 22$, MoHrip2 $\triangle \mathrm{C} 27$, MoHrip2 $\triangle \mathrm{C} 63$, and MoHrip2 $\triangle \mathrm{C} 77)$. Their abilities to induce HR in tobacco plants were evaluated, and although the first three mutants induced $\mathrm{HR}$, the last, most $\mathrm{N}$-terminal mutant could not (Figure 3C), suggesting that the MoHrip2 C-terminus might have a key function inducing HR. To verify this hypothesis, the MoHrip2 C-terminus was expressed (the $\mathrm{N}$-terminus was deleted, MoHrip2 $\triangle$ N75), and an HR induction assay was performed. The result showed that the C-terminus induced HR (Figure 3C), indicating that the above hypothesis was correct.

To further pinpoint the region responsible for HR induction, the middle part of MoHrip2 was isolated, and three truncated mutants, MoHrip2M50 (amino acid sequence from 76 to 125), MoHrip2M36 (amino acid sequence from 89 to 125), MoHrip2M14 (amino acid sequence from 76 to 89) were constructed based on the experimental results (Figure 3A). The HR induction assay showed that the MoHrip2M50 and MoHriop2M14 mutants induced HR in tobacco leaves, whereas MoHrip2M36 could not (Figure 3C). MoHriop2M14 and MoHrip2M36 were two independent parts of MoHrip2M50 (Figure 3A). The amino acid sequence of MoHrip2M14 was 


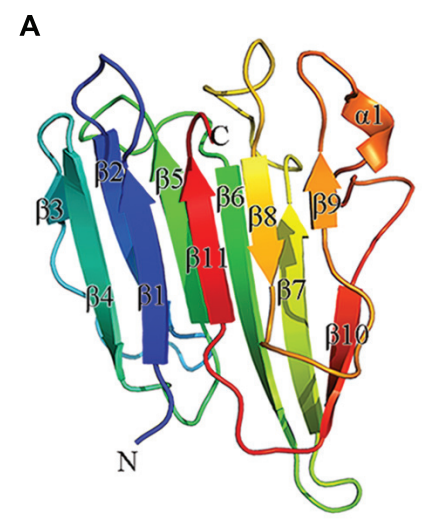

C

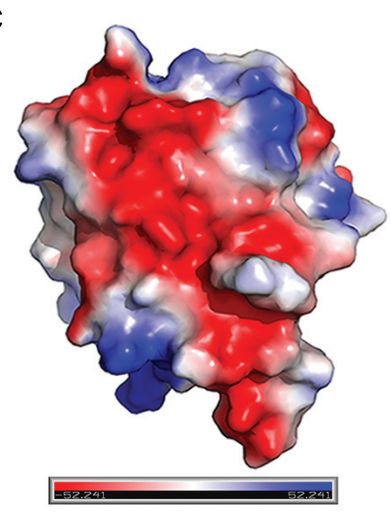

B

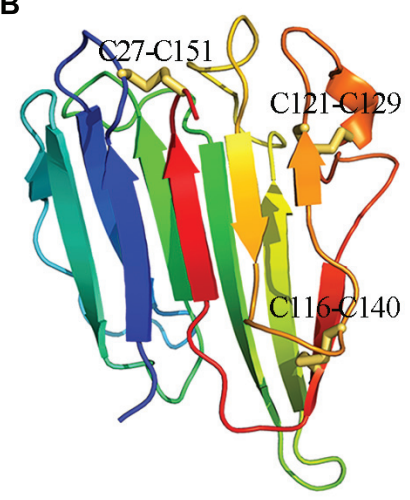

D

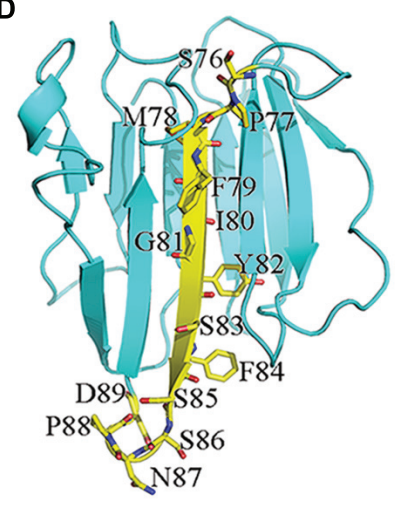

FIGURE 1 | Structural properties of the MoHrip2 protein. (A) Crystal structure of MoHrip2. There were two identical protein molecules in an asymmetric unit, and only one monomer is shown. MoHrip2 is depicted in ribbon representation (rainbow from blue to red), with the $\mathrm{N}$ and $\mathrm{C}$ termini and secondary structures labeled. (B) Three intramolecular disulfide bridges were formed by the six cysteines indicated in the structure. The disulfide bridges are shown in stick representation. (C) Electrostatic potential distribution on the molecular surface of MoHrip2. Blue and red represent negative and positive potentials, respectively. (D) A stretch of 14 amino acid residues. The 14 amino residues are shown in stick representation (yellow), with oxygen atoms colored red, and nitrogen atoms colored blue, in the context of the overall structure (cyan ribbon). All of the residues are labeled.

TABLE 2 | Results of pairwise superposition of MoHrip2 with representatives of the thaumatin-like protein family using the DaliLite v3 server (http://ekhidna.biocenter.helsinki.fi/dali_server).

\begin{tabular}{|c|c|c|c|c|c|c|}
\hline Protein & Source & PDB $^{\mathrm{a}}$ entry & Z-score ${ }^{b}$ & r.m.s.d $(\AA)$ & $\begin{array}{l}\text { No. of aligned } \\
\text { residues }\end{array}$ & Identity (\%) \\
\hline TL-XI & Triticum aestivum & $3 G 7 M$ & 13.1 & 2.6 & 123 & 18 \\
\hline Osmotin & Nicotiana tabacum & $1 \mathrm{PCV}$ & 12.3 & 2.3 & 126 & 22 \\
\hline Zeamatin & Zea mays & 1DU5 & 12.1 & 2.3 & 126 & 17 \\
\hline Beta-1,3-Glucanase & Streptomyces matensis & 3GD9 & 9.4 & 3.0 & 128 & 9 \\
\hline
\end{tabular}

a Protein Data Bank. ${ }^{\mathrm{b}}$ The Z-score is a measure of the quality of the alignment. The higher the Z-score, the more homologous the structures. A Z-score exceeding 2 is significant. ${ }^{\mathrm{c}}$ Root mean square deviation.

located in the central region of the polypeptide chain of MoHrip2 and contained 14 amino acid residues as shown in Figure 1D. All of the HR induction assays were performed using full-length MoHrip2 as the positive control and $\mathrm{His}_{6}$-Trx as the negative control (Figure 3C). To show all of the results in one tobacco leaf, N. tabacum cv. Samsun NN was used in the HR induction assay. The experiment was also performed on N. benthamiana and showed the same results as N. tabacum cv. Samsun NN (Supplementary Figure S3).
The HSR203 and HIN1 genes are considered HR molecular markers (Liu et al., 2006). The transcriptional level of these two genes was detected using qRT-PCR to verify whether HR induction was coincident with gene expression in the treated leaves. Using the actin gene as an internal control, qRT-PCR showed that the infiltration of leaves with MoHrip2, MoHrip2M50 or MoHrip2M14 induced up-regulation of HSR203 and HIN1 transcription $6 \mathrm{hpi}$, whereas leaves infiltrated with MoHrip2 $\triangle$ C77, MoHrip2M36 or His 6 -Trx 

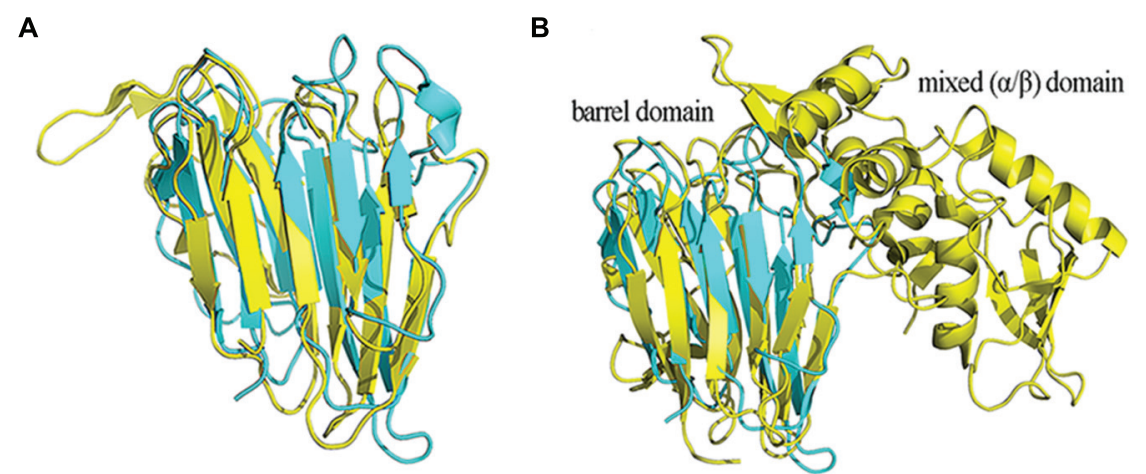

FIGURE 2 | The comparison of protein crystal structures. (A) Superposition of MoHrip2 with TL-XI (PDB 3G7M) from Triticum aestivum. (B) Superposition of MoHrip2 with Beta-1,3-Glucanase (PDB 3GD9) from T. aestivum. All of the structures are shown in ribbon representation. MoHrip2 is colored cyan, and TL-XI and Beta-1,3-Glucanase are colored yellow.

A

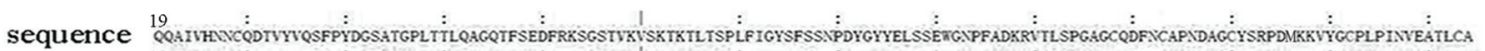

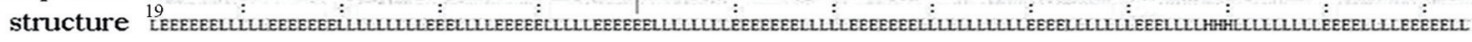

MoHrip 2
MoHrip $2 \triangle \mathrm{C} 22$
MoHrip $2 \triangle \mathrm{C} 27$
MoHrip $2 \triangle \mathrm{C} 63$
MoHrip $2 \triangle \mathrm{C} 77$
MoHrip $2 \triangle \mathrm{N} 75$
MoHrip2M50
MoHrip2M36
MoHrip2M14

B
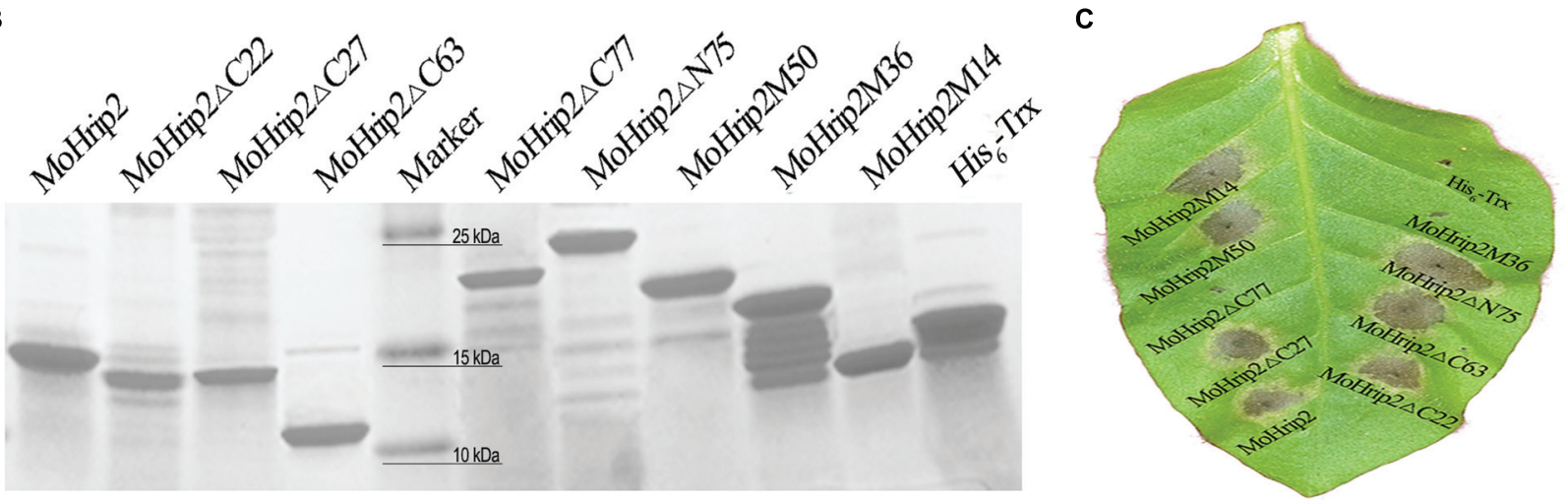

FIGURE 3 | The purification of truncated MoHrip2 mutants and their ability to induce HR. (A) Diagram of MoHrip2 and the truncated mutants that were used to test different regions of the protein for elicitor activity. The wide strips indicate spans of amino acid resides, and the strip color indicates the HR-inducing ability of different regions. Black indicates HR-inducing ability, and white indicates no HR-inducing ability. (B) SDS-PAGE analysis of proteins purified using a Ni-IMAC matrix column. MoHrip2 and the truncated mutants were expressed from different vectors and were coupled to different tags. Proteins 1-4 contained a His 6 tag. Proteins 5-9 contained a His 6 tag and a Trx-tag. (C) Macroscopic views of the HR symptoms induced by the prepared proteins at a concentration of $5 \mu \mathrm{M}$ in Nicotiana tabacum cv. Samsun NN. The photos were taken $24 \mathrm{~h}$ after infiltration.

showed less increase in transcript expression compared to untreated leaves (Figure 4A).

All of the above results indicated that the HR-inducing activity of MoHrip2M14 was equivalent to that of full-length MoHrip2, implying that the 14 amino acid residues play a crucial and independent role inducing HR. In other words, the HR-inducing activity of MoHrip2 is determined by these 14 amino acid residues. 
A

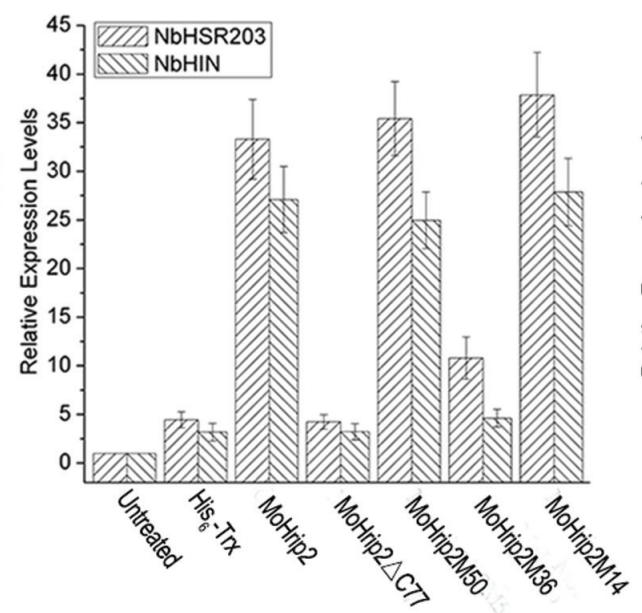

B

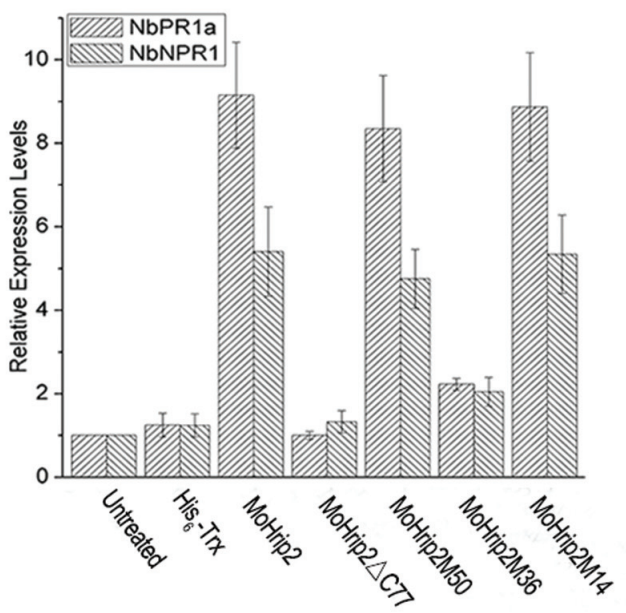

FIGURE 4 | Quantitative real-time PCR (qRT-PCR) results for representative HR and SAR marker genes in Nicotiana benthamiana leaves. (A) Relative expression levels of the HR marker genes HSR023 and HIN1. (B) Relative expression of SAR marker genes NPR1 and PR1a. The relative expression level of each gene was calculated as the fold change 6 hpi in leaves treated with the indicated proteins at a concentration of $5 \mu \mathrm{M}$ compared to untreated leaves. The Actin gene was used as an internal control to normalize the expression data. The data presented are the mean \pm standard deviation (SD) of three independent experiments, which showed similar results. The bars represent the SD $(n=3)$.

\section{MoHrip2 and HR-Inducing Truncated Fragments Enhance Resistance to $B$. cinerea in $\mathbf{N}$. benthamiana}

Considering that the MoHrip2M36 and MoHrip2M14 fragments showed significant differences in HR induction ability in $N$. benthamiana, a resistance assay was performed with MoHrip2, MoHrip2 $\triangle \mathrm{C} 77$ and the three middle fragments to test their ability to improve resistance to $B$. cinerea. $\mathrm{His}_{6}$-Trx was used as the negative control. N. benthamiana leaves were treated with different protein fragments and then incubated with $B$. cinerea mycelium, and the area of necrotic lesions was determined 3 dpi. The necrotic lesions in leaves treated with $\mathrm{His}_{6}$-Trx, MoHrip2 $\triangle \mathrm{C} 77$ and MoHrip2M36 were larger than in leaves treated with MoHrip2, MoHrip2M50, or MoHrip2M14 (Figure 5A). The area of the lesions was computed by measuring the lesion diameter or the major axes of oval-shaped lesions. The average lesion areas for $\mathrm{His}_{6}$-Trx-, MoHrip2 $\triangle \mathrm{C} 77$ and MoHrip2M36-treated leaves were $13.5 \pm 1.48 \mathrm{~cm}^{2}$, $13.5 \pm 1.54 \mathrm{~cm}^{2}$, and $12.6 \pm 1.60 \mathrm{~cm}^{2}$, respectively, whereas, the average lesion areas for MoHrip2-, MoHrip2M50-, and MoHrip2M14-treated leaves were $7.7 \pm 1.8 \mathrm{~cm}^{2}$, $8.1 \pm 1.37 \mathrm{~cm}^{2}$, and $7.6 \pm 1.72 \mathrm{~cm}^{2}$, respectively (Figure 5B).

$P R 1 a$ and NPR1 are important pathogenesis-related genes and systemic acquired resistance (SAR) pathway genes that are regarded as disease resistance marker genes. The transcript levels of the two genes, detected using qRT-PCR, were obviously up-regulated by the infiltration of MoHrip2, MoHrip2M50, or MoHrip2M14 into N. benthamiana leaves $6 \mathrm{hpi}$, but less increase was observed in leaves infiltrated with MoHrip2 $\triangle$ C77, MoHrip2M36 or $\mathrm{His}_{6}$-Trx compared to untreated leaves (Figure 4B). The gene actin was used as the internal control gene.
These results indicated that MoHrip2 significantly enhanced $N$. benthamiana resistance against the fungal pathogen $B$. cinerea and that the 14 amino acid residues have a crucial role in the induced resistance to pathogens. These results show that the functional region of MoHrip2 responsible for HR induction and disease resistance are in the same short region that contains the 14 crucial amino acid residues.

\section{DISCUSSION}

The MoHrip2 protein is a novel elicitor that was purified in our lab (NCBI locus XP_003709559) from M. oryzae 70-15; thus, there is little known about the functional regions of this protein. Our previous study showed that the MoHrip2 amino acid sequence was highly similar to that of proteins from several plant fungal pathogens (Chen et al., 2014). However, no additional information has been reported for these proteins.

In this study, the crystal structure of the protein elicitor MoHrip2 was determined. On the basis of the crystal structure, MoHrip2 showed a high similarity to the three-dimensional structure of a large family of proteins containing a thaumatinlike domain (Figure 2 and Table 2) despite the low homology of their primary sequences (Supplementary Figure S2). Of these proteins, we were interested in xylanase inhibitor TL-XI, to which MoHrip2 was most similar in three-dimensional structure (Figure 2A). The structure of MoHrip2 is also similar to that of the barrel domain of Beta-1,3-Glucanase (Figure 2B), which consists of a barrel domain and a mixed $(\alpha / \beta)$ domain, with a groove between the two domains. However, the MoHrip2 structure does not contain a mixed domain or the groove that is critical for binding the laminaritetraose (Wu et al., 2009), indicating that some inhibitors might have evolved from protease 
ancestors (Sansen et al., 2004) and highlighting the value of investigating the evolutionary history of MoHrip2.

The inhibitory effect of TL-XI on xylanase is just one example of an enzyme-inhibitor interaction at the plantpathogen interface. To invade plant cells, pathogens secrete several enzymes that degrade the cell wall in the plant apoplast, such as endo- $\beta-1,4$-xylanases (class GH10 and GH11) that degrade xylan, GH12 glucanases that degrade xyloglucan and polygalacturonases (PGs; class GH28) that hydrolyze homogalacturonan (Juge, 2006). In response, plants secrete many inhibitors to inhibit pathogen enzymes and thus protect themselves from invasion. In addition to TL-XI, several plant inhibitors, such as the TAXI, xylanase inhibitor protein (XIP), and polygalacturonase-inhibiting proteins (PGIPs) have been reported (Misas-Villamil and $\mathrm{Ra}, 2008$ ). Similarly, plants also secrete many hydrolases or proteinases that degrade the pathogen cell wall, but these molecules are targeted by pathogen-produced inhibitors such as glucanase inhibitor protein-1 (GIP1), which is secreted by Phytophthora sojae and targets the specific soybean endo- $\beta$-1,3-glucanases (Rose et al., 2002), AVR2 (avirulence protein 2) from the tomato fungal pathogen, and Cladosporium fulvum, which targets the tomato papain-like protease (Rooney et al., 2005). Interestingly, some inhibitor-enzyme complexes can act as elicitors and activate the plant defense system, including a complex of the protease RCR3 (required for Cladosporium resistance-3) with the inhibitor AVR2, which is recognized by the LRR receptor in tomato (Rooney et al., 2005). We hypothesize that MoHrip2 might be an inhibitor that can act with an enzyme(s) at the plant-pathogen surface when $M$. oryzae infects rice. One possibility is that MoHrip2 inhibits a degradation enzyme from $M$. oryzae to weaken pathogenicity at the stage of invading living rice cells (Qutob et al., 2002; Kankanala et al., 2007). The inhibitory effect of MoHrip2 on different enzymes from pathogens or plants will be tested in future studies to confirm the function of MoHrip2 during pathogenic infection. It is worth noting that all of the thaumatin-domain contained proteins with similar structures to MoHrip2 come from plants, which might be because of that this protein family is mainly found in plant and has not been reported in fungus.

Our results showed that MoHrip2 could enhance resistance to $B$. cinerea in tobacco (Figure 5) and induce the expression of pathogenesis-related genes and SAR pathway genes (Figure 4B), indicating that the MoHrip2 protein elicitor triggered a defense response to different pathogens in different plants. As an elicitor, the function of MoHrip2 in inducing HR and triggering a defense response to TMV in tobacco and to $M$. oryzae in rice had been reported in a previous study (Chen et al., 2014). As shown, MoHrip2 could induce cell death while enhance resistance to a necrotrophic pathogen, B. cinerea (Figures 3C and 5). Both HR marker genes and pahtogenesis-related genes were obviously up-regulated induced by MoHrip2 (Figure 4), indicating that MoHrip2 could activate diverse signaling pathways. Furthermore, Several protein elicitors were reported to play functions in different plants against different diseases. For examples, Hrip1, an HR-inducing protein isolated from the fungus Alternaria tenuissima, enhances disease resistance to TMV in tobacco and to B. cinerea in Arabidopsis (Kulye et al., 2012; Peng et al., 2015). The protein elicitor PevD1, which was isolated from the fungal pathogen Verticillium dahlia, enhances resistance to TMV in tobacco and to Verticillium wilt in cotton
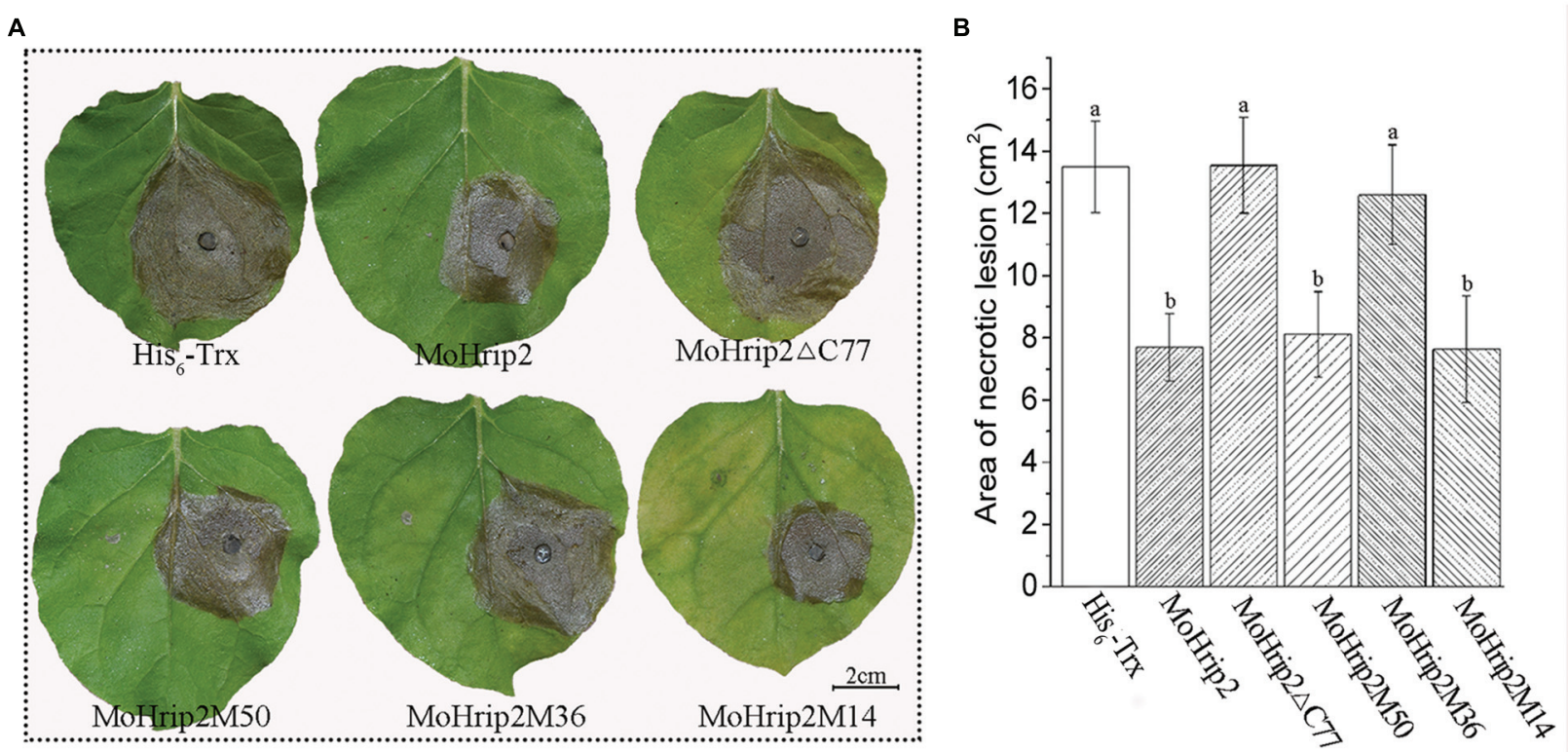

FIGURE 5 | The effects of the indicated proteins on Botrytis cinerea infection in $\mathbf{N}$. benthamiana. (A) The symptoms of B. cinerea infection 3 dpi. (B) Necrotic lesion area caused by $B$. cinerea infection $3 \mathrm{dpi}$. B. cinerea was inoculated 6 hpi on $N$. benthamiana leaves treated with the indicated proteins at a concentration of $5 \mu \mathrm{M}$. The data presented were the mean \pm SD of three independent experiments that showed similar results. The bars represent the SD ( $n=3$ ). Different letters on SD bars indicated significant differences between compared plants using one-way ANOVA and Fisher's Least (LSD) test ( $P$ < 0.01). 
(Bu et al., 2014; Liu et al., 2014). All of these results indicate that some protein elicitor showed a broad range of function on disease resistance inducing in different treated plants.

To identify the functional region of MoHrip2 required for its activity, eight truncated mutants were expressed and purified, and the ability of MoHrip2 and the mutants to induce HR and defense responses was investigated. The results indicated that different regions of MoHrip2 had different effects on induction ability. The 14 amino acid residues located in the middle region form the functional region responsible for the HR and the disease-resistance induction (Figures 3 and 5) of the MoHrip2 elicitor. These 14 residues include a $\beta$-strand within a $\beta$-barrel and part of two neighboring loops (Figure 1D). During the process of HR induction when interacting with its target, MoHrip2 might undergo local conformational changes around this stretch, especially in the loop regions, to expose active residues necessary for function. Previous reports have indicated that functional region can be located in the same or different regions of an elicitor. The region between amino acids 35 and 53 of HapG, identified in Xanthomonas axonopodis pv. glycines, induced HR and exhibited elicitor activity (Kim et al., 2004). $\mathrm{HpaG}_{62-137}$, a region of $\mathrm{HpaG}_{\text {Xooc }}$ identified in Xanthomonas oryzae pv. oryzicola, induced HR in tobacco as well as stimulated a defense response and enhanced growth in rice (Chen et al., 2008). However, although the $\mathrm{HpaG}_{10-42}$ region did not induce HR in tobacco, it stimulated a stronger defense response and enhanced more growth in rice than the full-length parental protein (Zhao et al., 2014). The C-terminal 57 amino acid residues of the elicitor PevD1 are critical for inducing HR; however, the N-terminal 98 amino acid residues do not induce HR but retained the ability to enhance resistance against TMV in tobacco (Liu et al., 2014). The 14 amino acid residues in the middle region of MoHrip2 retained both the ability to induce HR and to enhance resistance in tobacco.

\section{CONCLUSION}

We solved the three-dimensional structure of the elicitor protein MoHrip2, which showed a high similarity to PR-5 family proteins containing a thaumatin-like domain. Mutation and deletion analysis based on the structure of MoHrip2 specified the region

\section{REFERENCES}

Abad, L. R., D’Urzo, M. P., Liu, D., Narasimhan, M. L., Reuveni, M., Zhu, J. K., et al. (1996). Antifungal activity of tobacco osmotin has specificity and involves plasma membrane permeabilization. Plant Sci. 118, 11-23. doi: 10.1016/01689452(96)04420-2

Adams, P. D., Afonine, P. V., Bunkoczi, G., Chen, V. B., Davis, I. W. Echols, N., et al. (2010). PHENIX: a comprehensive Python-based system for macromolecular structure solution. Acta Crystallogr. D Biol. Crystallogr. 66, 213-221. doi: 10.1107/S0907444909052925

Afonine, P. V., Grosse-Kunstleve, R. W., Echols, N., Headd, J. J., Moriarty, N. W., Mustyakimov, M., et al. (2012). Towards automated crystallographic structure refinement with phenix.refine. Acta Crystallogr. D Biol. Crystallogr. 68, 352-367. doi: 10.1107/S0907444912001308 that is essential for MoHrip2 elicitor function. A stretch of 14 amino acid residues in the central region of MoHrip2 play essential and independent roles in inducing HR and enhancing disease resistance in tobacco. These results provide a framework for understanding MoHrip2 function at the molecular level in $M$. oryzae and in plants in general. Considering their effects on plant growth and the possibility that overexpression can induce disease resistance (Zhao et al., 2014), short genes might cause fewer adverse effects in transgenic plants. Moreover, as $\mathrm{HpaG}_{10-42}$ showed more activity promoting plant growth and defense than HpaG (Chen et al., 2008), the short active region of MoHrip2 might increase the defensive capabilities in vitro or in transgenic plants. We will address these issues in future studies.

\section{AUTHOR CONTRIBUTIONS}

DQ, XL, and ML conceived the project and designed the experiments. ML purified and crystallized MoHrip2, designed and expressed mutant proteins and analyzed mutant protein function in plant. XL determined the X-ray structure. ML, MW, and LD analyzed the data. ML and MW wrote the paper. HZ contributed essential materials. All of the authors reviewed the manuscript.

\section{FUNDING}

This work was supported by the National Natural Science Foundation of China (No. 31371984).

\section{ACKNOWLEDGMENTS}

We wish to express our gratitude to Prof. Xiufen Yang (Institute of Plant Protection - Chinese Academy of Agricultural Sciences) for useful discussions.

\section{SUPPLEMENTARY MATERIAL}

The Supplementary Material for this article can be found online at: http://journal.frontiersin.org/article/10.3389/fpls.2016.01103

Bernoux, M., Ellis, J. G., and Dodds, P. N. (2011). New insights in plant immunity signaling activation. Curr. Opin. Plant Biol. 14, 512-518. doi: 10.1016/j.pbi.2011.05.005

Bos, J. I. B., Kanneganti, T.-D., Young, C., Cakir, C., Huitema, E., Win, J., et al. (2006). The C-terminal half of Phytophthora infestans RXLR effector AVR3a is sufficient to trigger R3a-mediated hypersensitivity and suppress INF1-induced cell death in Nicotiana benthamiana. Plant J. 48, 165-176. doi: 10.1111/j.1365313X.2006.02866.x

Bradford, M. M. (1976). A rapid and sensitive method for the quantitation of microgram quantities of protein utilizing the principle of protein-dye binding. Anal. Biochem. 72, 248-254. doi: 10.1016/0003-2697(76)90527-3

Bu, B., Qiu, D., Zeng, H., Guo, L., Yuan, J., and Yang, X. (2014). A fungal protein elicitor PevD1 induces Verticillium wilt resistance in cotton. Plant Cell Rep. 33, 461-470. doi: 10.1007/s00299-013-1546-7 
Bustin, S. A., Benes, V., Garson, J. A., Hellemans, J., Huggett, J., Kubista, M., et al. (2009). The MIQE guidelines: minimum information for publication of quantitative real-time PCR experiments. Clin. Chem. 55, 611-622. doi: 10.1373/clinchem.2008.112797

Chagué, V., Danit, L.-V., Siewers, V., Gronover, C. S., Tudzynski, P., Tudzynski, B., et al. (2006). Ethylene sensing and gene activation in botrytis cinerea: a missing link in ethylene regulation of fungus-plant interactions? Mol. Plant Microbe Interact. 19, 33-42. doi: 10.1094/MPMI-19-0033

Chen, L., Qian, J., Qu, S., Long, J., Yin, Q., Zhang, C., et al. (2008). Identification of specific fragments of HpaGXooc, a harpin from Xanthomonas oryzae pv. oryzicola, that induce disease resistance and enhance growth in plants. Phytopathology 98, 781-791. doi: 10.1094/PHYTO-98-7-0781

Chen, M., Zhang, C., Zi, Q., Qiu, D., Liu, W., and Zeng, H. (2014). A novel elicitor identified from Magnaporthe oryzae triggers defense responses in tobacco and rice. Plant Cell Rep. 33, 1865-1879. doi: 10.1007/s00299-014-1663-y

Chuang, H.-W., Chang, P.-Y., and Syu, Y.-Y. (2014). Harpin protein, an elicitor of disease resistance, acts as a growth promoter in Phalaenopsis orchids. J. Plant Growth Regul. 33, 788-797. doi: 10.1007/s00344-014-9425-1

Dauter, Z., Dauter, M., and Dodson, E. (2002). Jolly SAD. Acta Crystallogr. D 58, 494-506. doi: 10.1107/S090744490200118X

Dean, R. A., Talbot, N. J., Ebbole, D. J., Farman, M. L., Mitchell, T. K., Orbach, M. J., et al. (2005). The genome sequence of the rice blast fungus Magnaporthe grisea. Nature 434, 980-986. doi: 10.1038/nature03449

Dodds, P. N., and Rathjen, J. P. (2010). Plant immunity: towards an integrated view of plant-pathogen interactions. Nat. Rev. Genet. 11, 539-548. doi: $10.1038 / \mathrm{nrg} 2812$

D’Silva, I., and Heath, M. C. (1997). Purification and characterization of two novel hypersensitive response-inducing specific elicitors produced by the cowpea rust fungus. J. Biol. Chem. 272, 3924-3927. doi: 10.1074/jbc.272.7.3924

Edens, L., Heslinga, L., Klok, R., Ledeboer, A. M., Maat, J., Toonen, M. Y., et al. (1982). Cloning of cDNA encoding the sweet-tasting plant protein thaumatin and its expression in Escherichia coli. Gene 18, 1-12. doi: 10.1016/03781119(82)90050-6

Ferrari, S., Plotnikova, J. M., De Lorenzo, G., and Ausubel, F. M. (2003). Arabidopsis local resistance to Botrytis cinerea involves salicylic acid and camalexin and requires EDS4 and PAD2, but not SID2, EDS5 or PAD4. Plant J. 35, 193-205. doi: 10.1046/j.1365-313X.2003.01794.x

Fierens, E., Rombouts, S., Gebruers, K., Goesaert, H., Brijs, K., Beaugrand, J., et al. (2007). TLXI, a novel type of xylanase inhibitor from wheat (Triticum aestivum) belonging to the thaumatin family. Biochem. J. 403, 583-591. doi: 10.1042/bj20061291

Ghosh, R., and Chakrabarti, C. (2008). Crystal structure analysis of NP24I: a thaumatin-like protein. Planta 228, 883-890. doi: 10.1007/s00425-0080790-5

Han, L., Liu, Z., Liu, X., and Qiu, D. (2012). Purification, crystallization and preliminary X-ray diffraction analysis of the effector protein PevD1 from Verticillium dahliae. Acta Crystallogr. Sect. F Struct. Biol. Cryst. Commun. 68, 802-805. doi: 10.1107/S1744309112020556

Holm, L., and Rosenström, P. (2010). Dali server: conservation mapping in 3D. Nucleic Acids Res. 38, W545-W549. doi: 10.1093/nar/gkq366

Hou, S., Zhang, C., Yang, Y., and Wu, D. (2013). Recent advances in plant immunity: recognition, signaling, response, and evolution. Biol. Plant. 57, 11-25. doi: 10.1007/s10535-012-0109-z

Hwang, I. S., Kim, N. H., Choi, D. S., and Hwang, B. K. (2012). Overexpression of Xanthomonas campestris pv. vesicatoria effector AvrBsT in Arabidopsis triggers plant cell death, disease and defense responses. Planta 236, 1191-1204. doi: 10.1007/s00425-012-1672-4

Jones, J. D. G., and Dangl, J. L. (2006). The plant immune system. Nature 444, 323-329. doi: $10.1038 /$ nature 05286

Juge, N. (2006). Plant protein inhibitors of cell wall degrading enzymes. Trends Plant Sci. 11, 359-367. doi: 10.1016/j.tplants.2006.05.006

Kankanala, P., Czymmek, K., and Valent, B. (2007). Roles for rice membrane dynamics and plasmodesmata during biotrophic invasion by the blast fungus. Plant Cell 19, 706-724. doi: 10.1105/tpc.106.046300

Kim, J.-G., Jeon, E., Oh, J., Moon, J. S., and Hwang, I. (2004). Mutational analysis of Xanthomonas Harpin HpaG identifies a key functional region that elicits the hypersensitive response in nonhost plants. J. Bacteriol. 186, 6239-6247. doi: 10.1128/jb.186.18.6239-6247.2004
Koga, J., Yamauchi, T., Shimura, M., Ogawa, N., Oshima, K., Umemura, K., et al. (1998). Cerebrosides A and C, sphingolipid elicitors of hypersensitive cell death and phytoalexin accumulation in rice plants. J. Biol. Chem. 273, 31985-31991. doi: 10.1074/jbc.273.48.31985

Kulye, M., Liu, H. U. A., Zhang, Y., Zeng, H., Yang, X., and Qiu, D. (2012). Hrip1, a novel protein elicitor from necrotrophic fungus, Alternaria tenuissima, elicits cell death, expression of defence-related genes and systemic acquired resistance in tobacco. Plant Cell Environ. 35, 2104-2120. doi: 10.1111/j.13653040.2012.02539.x

Laskowski, R. A., MacArthur, M. W., Moss, D. S., and Thornton, J. M. (1993). PROCHECK: a program to check the stereochemical quality of protein structures. J. Appl. Crystallogr. 26, 283-291. doi: 10.1107/S00218898920 09944

Liu, F., Liu, H., Jia, Q., Wu, X., Guo, X., Zhang, S., et al. (2006). The internal glycinerich motif and cysteine suppress several effects of the HpaGXooc protein in plants. Phytopathology 96, 1052-1059. doi: 10.1094/PHYTO-96-1052

Liu, J., Wang, X., Mitchell, T., Hu, Y., Liu, X., Dai, L., et al. (2010). Recent progress and understanding of the molecular mechanisms of the rice-Magnaporthe oryzae interaction. Mol. Plant Pathol. 11, 419-427. doi: 10.1111/j.13643703.2009.00607.x

Liu, M., Liu, X., Zeng, H., and Qiu, D. (2013). Purification, crystallization and preliminary X-ray diffraction analysis of effector protein MoHrip2 from Magnaporthe oryzae. Acta Crystallogr. Sect. F Struct. Biol. Cryst. Commun. 69, 463-467. doi: 10.1107/S1744309113007094

Liu, T., Liu, Z., Song, C., Hu, Y., Han, Z., She, J., et al. (2012). Chitin-induced dimerization activates a plant immune receptor. Science 336, 1160-1164. doi: $10.1126 /$ science. 1218867

Liu, W., Zeng, H., Liu, Z., Yang, X., Guo, L., and Qiu, D. (2014). Mutational analysis of the Verticillium dahliae protein elicitor PevD1 identifies distinctive regions responsible for hypersensitive response and systemic acquired resistance in tobacco. Microbiol. Res. 169, 476-482. doi: 10.1016/j.micres.2013.08.001

Maqbool, A., Saitoh, H., Franceschetti, M., Stevenson, C. E. M., Uemura, A., Kanzaki, H., et al. (2015). Structural basis of pathogen recognition by an integrated HMA domain in a plant NLR immune receptor. Elife 4, 1-24. doi: 10.7554/elife.08709

Misas-Villamil, J. C., and Ra, V. D. H. (2008). Enzyme-inhibitor interactions at the plant-pathogen interface. Curr. Opin. Plant Biol. 11, 380-388. doi: 10.1016/j.pbi.2008.04.007

Mishra, A. K., Sharma, K., and Misra, R. S. (2012). Elicitor recognition, signal transduction and induced resistance in plants. J. Plant Interact. 7, 95-120. doi: 10.1080/17429145.2011.597517

Peng, X.-C., Qiu, D.-W., Zeng, H.-M., Guo, L.-H., Yang, X.-F., and Liu, Z. (2015). Inducible and constitutive expression of an elicitor gene Hrip1 from Alternaria tenuissima enhances stress tolerance in Arabidopsis. Transgenic Res. 24, 135-145. doi: 10.1007/s11248-014-9824-x

Qutob, D., Kamoun, S., and Gijzen, M. (2002). Expression of a Phytophthora sojae necrosis-inducing protein occurs during transition from biotrophy to necrotrophy. Plant J. 32, 361-373. doi: 10.1046/j.1365-313x.2002.01439.x

Roberts, W. K., and Selitrennikoff, C. P. (1990). Zeamatin, an antifungal protein from maize with membrane-permeabilizing activity. Microbiology 136, 17711778. doi: 10.1099/00221287-136-9-1771

Rooney, H. C. E., Klooster, J. W. V. T., Hoorn, R. A. L. V. D., Joosten, M. H. A. J., Jones, J. D. G., and Wit, P. J. G. M. D. (2005). Cladosporium Avr2 inhibits tomato Rcr3 protease required for Cf-2-dependent disease resistance. Science 308, 1783-1786. doi: 10.2307/3841674

Rose, J. K. C., Ham, K.-S., Darvill, A. G., and Albersheim, P. (2002). Molecular cloning and characterization of glucanase inhibitor proteins: coevolution of a counterdefense mechanism by plant pathogens. Plant Cell 14, 1329-1345. doi: $10.2307 / 3871607$

Sansen, S., De Ranter, C. J., Gebruers, K., Brijs, K., Courtin, C. M., Delcour, J. A., et al. (2004). Structural basis for inhibition of Aspergillus niger xylanase by Triticum aestivum xylanase inhibitor-I. J. Biol. Chem. 279, 36022-36028. doi: 10.1074/jbc.m404212200

Shamrai, S. N. (2014). Plant immune system: basal immunity. Cytol. Genet. 48, 258-271. doi: 10.3103/S0095452714040057

Vigers, A. J., Wiedemann, S., Roberts, W. K., Legrand, M., Selitrennikoff, C. P., and Fritig, B. (1992). Thaumatin-like pathogenesis-related proteins are antifungal. Plant Sci. 83, 155-161. doi: 10.1016/0168-9452(92)90074-V 
Wang, L., Yang, L., Zhang, J., Dong, J., Yu, J., Zhou, J., et al. (2013). Cloning and characterization of a thaumatin-like protein gene PeTLP in Populus deltoides $\times$ P. euramericana cv. 'Nanlin895'. Acta Physiol. Plant. 35, 2985-2998. doi: 10.1007/s11738-013-1330-x

Wirthmueller, L., Maqbool, A., and Banfield, M. J. (2013). On the front line: structural insights into plant-pathogen interactions. Nat. Rev. Microbiol. 11, 761-776. doi: 10.1038/nrmicro3118

Wu, H.-M., Liu, S.-W., Hsu, M.-T., Hung, C.-L., Lai, C.-C., Cheng, W.-C., et al. (2009). Structure, mechanistic action, and essential residues of a GH-64 enzyme, laminaripentaose-producing $\beta$-1,3-glucanase. J. Biol. Chem. 284, 26708-26715. doi: 10.1074/jbc.M109.010983

Zhao, Y., Li, C., Ge, J., Xu, M., Zhu, Q., Wu, T., et al. (2014). Recessive mutation identifies auxin-repressed protein ARP1, which regulates growth and disease resistance in tobacco. Mol. Plant Microbe Interact. 27, 638-654. doi: 10.1094/MPMI-08-13-0250-R
Zhu, M., Shao, F., Innes, R. W., Dixon, J. E., and Xu, Z. (2004). The crystal structure of Pseudomonas avirulence protein AvrPphB: a papain-like fold with a distinct substrate-binding site. Proc. Natl. Acad. Sci. U.S.A. 101, 302-307. doi: 10.1073/pnas.2036536100

Conflict of Interest Statement: The authors declare that the research was conducted in the absence of any commercial or financial relationships that could be construed as a potential conflict of interest.

Copyright (C) 2016 Liu, Duan, Wang, Zeng, Liu and Qiu. This is an open-access article distributed under the terms of the Creative Commons Attribution License (CC BY).

The use, distribution or reproduction in other forums is permitted, provided the original author(s) or licensor are credited and that the original publication in this journal is cited, in accordance with accepted academic practice. No use, distribution or reproduction is permitted which does not comply with these terms. 